\title{
Ultrastructure of Spironucleus salmonis n. comb. (formerly Octomitus salmonis sensu Moore 1922, Davis 1926, and Hexamita salmonis sensu Ferguson 1979), with a guide to Spironucleus species
}

\author{
Sarah L. Poynton ${ }^{1,2, *}$, M. Reza Saghari Fard ${ }^{2,3}$, John Jenkins ${ }^{4}{ }^{4}$ Hugh W. Ferguson ${ }^{5}$ \\ ${ }^{1}$ Department of Comparative Medicine, Johns Hopkins University School of Medicine, Broadway Research Building, \\ 733 North Broadway, Room 807, Baltimore, Maryland 21205, USA \\ ${ }^{2}$ Department of Inland Fisheries, Leibniz-Institute of Freshwater Ecology and Inland Fisheries, Müggelseedamm 310, \\ 12587 Berlin, Germany \\ ${ }^{3} \mathrm{MSc}$ in International Agricultural Sciences, College of Agriculture and Horticulture, Humboldt University Berlin, \\ Invalidenstrasse 42, 10115 Berlin, Germany \\ ${ }^{4}$ Department of Veterinary Pathology, Armed Forces Institute of Pathology, Washington, DC 20306, USA \\ ${ }^{5}$ Institute of Aquaculture, University of Stirling, Stirling FK9 4LA, UK
}

\begin{abstract}
Diplomonad flagellates can be associated with significant morbidity and mortality in fishes, particularly in farmed salmonids. Diagnosis using only light microscopy is limited, and species cannot be confirmed. We therefore undertook a comprehensive transmission electron microscopy study of 20 trophozoites from the intestine of farmed juvenile rainbow trout Oncorhynchus mykiss from Northern Ireland (reported as Hexamita salmonis by Ferguson in 1979). Re-assignment to the genus Spironucleus was determined based on the anteriorly tapering and intertwined elongate nuclei, anterior-medial kinetosomes, and the presence of a flagellar pocket. At the species level we observed a tri-radiate pattern of microtubules in the opening of the asymetrical striated lamina, comprising 3 to 5 microtubules following the edge of the flagellar pocket, 3 radiating away from the opening of the striated lamina, and 4 to 5 curving over the striated lamina. We observed electron-dense plaques adjacent to the kinetosomes, electron-dense bodies, numerous free ribosomes, aggregations of glycogen, bowl-shaped membranous structures, rough endoplasmic reticulum, and a novel distinctive pyriform sac of densely packed free ribosomes at the posterior of the cell (8-shaped in transverse section, and delineated by furrowed endoplasmic reticulum). We now propose to rename $H$. salmonis sensu Ferguson (1979) Spironucleus salmonis. Our review of the morphology of Octomitus salmonis illustrated by Moore (1922a,b) and Davis (1926), has shown that this organism also belongs to the genus Spironucleus. We synonymise H. salmonis sensu Ferguson (1979) with O. salmonis sensu Moore (1922) and Davis (1926), and rename them S. salmonis. An expanded diagnostic guide, including new cytoplasmic elements, is presented for the 4 species of Spironucleus from fishes $(S$. barkhanus, S. salmonis, S. torosa and S. vortens). We recommend that type descriptions of diplomonads be based on organisms taken directly from the host rather than from in vitro culture in order to reliably include the cytoplasmic organelles.
\end{abstract}

KEY WORDS: Diplomonad · Flagellate · Hexamita salmonis · Oncorhynchus mykiss · Rainbow trout · Spironucleus salmonis $\cdot$ Ultrastructure

\section{INTRODUCTION}

Diplomonad flagellates infect shellfishes, fishes, and amphibia (Woo \& Poynton 1995). They occur in fresh- water and marine fishes, in aquaculture and in the wild, especially in salmonids, cichlids, gadids and cyprinids, and they have been reported from cold, temperate and warm waters in North America, Asia and 
Europe. The flagellates are commonly found in the gut lumen, and less commonly in skin and systemic infections. Both intestinal and systemic infections are associated with significant morbidity and mortality in aquaculture (Moore 1922a,b, Allison 1963, Hare \& Frantsi 1974, Ferguson 1979, Poynton \& Morrison 1990, Awakura 1992, Kent et al. 1992, Poppe et al. 1992, Poynton et al. 1995, Woo \& Poynton 1995, Uldal \& Buchmann 1996, Sterud et al. 1997, 1998, Sterud 1998b).

Despite the common occurrence of diplomonads, and the associated problematic infections, they are poorly understood parasites. In particular, our knowledge of morphological and ultrastructural characterisation of species is limited, and consequently our knowledge of host-parasite specificity, geographic ranges, functional morphology and pathogenicity of different species is also limited. Inadequate recognition of genus and species contributes to much confusion in the literature. Although 3 diplomonad genera (Hexamita, Octomitus, and Spironucleus) and 15 to 20 species have been reported from fishes, most of these descriptions are incomplete, comprising only light microscopy (Poynton \& Sterud 2002). Scanning and transmission electron microscopy are now recognised as essential for accurate identification of genus and species (Poynton \& Sterud 2002).

Diplomonads have long been known from salmonids, including an early report in 1903 of Urophagus intestinalis (syn. Hexamitus intestinalis) from rainbow trout Oncorhynchus mykiss in Europe (Moroff 1903). Some 17 yr later, these organisms were described from trout in Germany and referred to as Octomitus intestinalis truttae by Schmidt (1919/1920). Shortly thereafter, Octomitus salmonis was described from brook trout Salvelinus fontinalis, brown trout Salmo trutta, rainbow trout O. mykiss, and lake trout Salvelinus namaycush, from a hatchery in Bath, New York State, on the east coast of North America (type description by Moore 1922a; elaborated upon by Moore 1922b and Davis 1926). Moore (1922a,b) distinguished the American trout diplomonad from the European trout diplomonad based on differences in size of nuclei, 'relation of the axostyles' in trophozoites and cysts, and presence or absence of caudal grooves. She also noted that the American species of trout diplomonad caused serious lesions in the intestinal epithelium and disease (weakness, watery intestinal contents and death of fingerlings), whereas the European species was reported to be a commensal (Moore 1922a,b). Later reports, beginning with Wenyon (1926), refer to O. salmonis as Hexamita salmonis, and the latter name has now entered common usage. The exact identity of the diplomonads described by the European and North American authors, and their possible synonymy, has been considered but not resolved (Kulda \& Lom 1964).

Since publication of the papers by Moore $(1922 a, b)$ and Davis (1926), most diplomonad infections in salmonids - and indeed some infections in nonsalmonids (Lester 1974) — have been studied by light microscopy only, and reported as Hexamita salmonis. Some taxonomic progress was made in 1979 by Ferguson, who published preliminary ultrastructural work (scanning electron microscopy [SEM] and transmission electron microscopy [TEM]), on a diplomonad from juvenile rainbow trout in Northern Ireland, which he reported as $H$. salmonis. Up to that point, diplomonads from salmonids had only been reported as belonging to the genus Hexamita or Octomitis (Spironucleus, first described by Lavier in 1936 from amphibians, had subsequently been reported from non-salmonids, including eels and cichlids; Kulda \& Lom 1964). In 1990, Poynton \& Morrison published limited SEM descriptions of a diplomonad from brook trout in Canada, which they also reported as H. salmonis. In 1992, Kent et al. presented a limited TEM study of an unnamed pathogenic hexamitid from adult Chinook salmon Oncorhynchus tshawytscha in western Canada. In 1997, Sterud et al. described, by SEM and TEM, a new pathogenic species (Spironucleus barkhanus) from adult grayling Thymallus thymallus and Atlantic salmon Salmo salar from Norway, and discussed the possibility of it being synonymous with $H$. salmonis. None of the 4 aforementioned ultrastructural studies resolved the question of the true identity and characterisation of $H$. salmonis.

Our present studies were prompted by the continued uncertainty over the identity of diplomonads from trout, and facilitated by the recent establishment of guidelines for the species descriptions of diplomonad flagellates from fishes (Poynton \& Sterud 2002), and the availability of the original TEM grids bearing sections of the diplomonad from rainbow trout in Northern Ireland, initially described as Hexamita salmonis by Ferguson (1979). We intended that our ultrastructural studies would not only answer taxonomic questions, but also indicate suitable target organelles or structures for species-specific light microscopy diagnostic tests, and reveal insights into the functional morphology of the diplomonad cell. Improved speciesspecific light microscopical diagnostic tests for diplomonads are urgently needed, because for most diagnostic laboratories electron microscopy is too expensive and time consuming for routine use, and molecular taxonomy of diplomonads from fishes is still in its infancy (Poynton \& Sterud 2002).

We re-examined the grids prepared by Ferguson (1979), and now present ultrastructural characterisation of 'Hexamita salmonis', which belongs not in the 
genus Hexamita, but in the genus Spironucleus. Comparison of our results with the ultrastructure of the 3 other well-characterised diplomonads from fishes $(S$. barkhanus Sterud, Mo \& Poppe, 1997, S. torosa Poynton \& Morrison, 1990, and S. vortens Poynton, Fraser, Francis-Floyd, Rutledge, Reed \& Nerad, 1995) has enabled us to prepare a guide for their ultrastructural diagnosis based on surface morphology and cytoskeletal and cytoplasmic features.

We also reviewed the morphology of Octomitus salmonis presented in the line drawings of Moore (1922a,b) and Davis (1926), and recognise that this organism also belongs in the genus Spironucleus. We propose to synonymise Hexamita salmonis sensu Ferguson (1979) with Octomitus salmonis sensu Moore (1922a,b) and Davis (1926), and rename them Spironucleus salmonis.

\section{MATERIALS AND METHODS}

Source of material. In the present study we reexamined the material collected by Ferguson and initially described as Hexamita salmonis (Ferguson 1979). The diplomonads were obtained in April/May 1978 from juvenile rainbow trout from a farm on the Clogh River (part of the Main River) in Northern Ireland. The fish, which had been fed a commercially prepared diet, had experienced an increase in mortality, concomitant with heavy diplomonad infections in the intestine. Sick fish, approximately $5 \mathrm{~cm}$ long, were found at the tail of the concrete raceways, where they exhibited a spiralling motion. Abdominal cavities were swollen, due to accumulation of ascitic fluid. No inflammation or necrosis of the intestine was seen, even in regions with the highest density of infection. Hepatocellular necrosis was marked and had a multi-focal distribution.

Preparation and examination of electron microscope samples. After decapitation of the fish, intestines were slit open and cut into small blocks. Tissue was fixed in $2 \%$ cacodylate-buffered glutaraldehyde $(\mathrm{pH}$ 7.2 and total osmolality of approximately $320 \mathrm{mOsm}$ ) for $1 \mathrm{~h}$ at $4^{\circ} \mathrm{C}$, followed by post-fixation for $1 \mathrm{~h}$ at $4{ }^{\circ} \mathrm{C}$ in $1 \%$ phosphate-buffered osmium tetroxide, with no intervening buffered rinse. The tissue was dehydrated in graded ethanols. For TEM, tissues were then embedded in Araldite Epon resin. Ultrathin sections were stained with uranyl acetate and lead citrate. Our re-examination involved taking high-magnification transmission electron micrographs of 20 organisms that showed taxonomically useful features (Poynton \& Sterud 2002).

The SEM samples from Ferguson (1979) were no longer available, and the current paucity of diplo- monad infections at the Northern Ireland farm precluded collection of new samples.

Identification to genus. Our re-examination of material was based upon the pioneering work of Brugerolle $(1974,1975)$, and Brugerolle et al. $(1973,1974)$; and the recent syntheses by Brugerolle \& Lee (2002) and Poynton \& Sterud (2002). Of particular importance were the shape of the nuclei, location of kinetosomes relative to the nuclei, and position of recurrent flagella relative to the nuclei; the presence or absence of flagellar pockets, a central axis formed by recurrent axonemes, and 2 terminal spikes; and the extent of the supra-nuclear microtubular band and infra-nuclear microtubular band.

Characterisation of species. The diplomonad was characterised at the species level following the recommendations of Poynton \& Sterud (2002), with particular attention being focused on the cytoskeleton (pattern of microtubular bands accompanying the flagellar pocket, and other cytoskeletal elements) and the diversity and distribution of cytoplasmic organelles.

Prior observations. Ferguson's prior study (1979) focused on the pathological changes, and aside from cytoplasmic blebbing and apoptosis of mucosal epithelium, he reported 'no evidence of any significant changes in the intestinal mucosa despite, in some cases, a heavy infection with Hexamita which were often in direct contact with the brush border.' Despite this, treatment of the fish to remove the parasites, by administration of furazolidone for $14 \mathrm{~d}$ at $75 \mathrm{mg} \mathrm{kg}^{-1}$ fish, greatly reduced mortalities.

Ferguson (1979) described the pear-shape of the diplomonads, with 3 anterior pairs of flagella and 1 posterior pair. The cell membrane was smooth, regular, and thin. Flagella and basal bodies were 'of typical structure' and nuclei were anterior. Electron-dense bodies and limited amounts of endoplasmic reticulum were observed. Golgi apparatus, mitochondria, or evidence of endocytosis were not seen. In 1979, the features by which genera and species of diplomonads from fishes could be differentiated were not widely known, and thus it was not clear which features were of taxonomic value.

Diagnostic guide to species. We are now able to expand the table of comparative ultrastructure provided by Poynton \& Sterud (2002) (which focused upon surface features and cytoskeletal elements) by the addition of cytoplasmic elements, and information about the presence of symbiotic bacteria and possible attachment of the diplomonad to host tissue. In compiling the enlarged table, we re-examined not only the Hexamita salmonis material, but also all published ultrastructural studies of diplomonads from fishes: Spironucleus barkhanus (Sterud et al. 1997, 1998), S. torosa (Poynton \& Morrison 1990, Sterud 1998a,c), and S. vortens (Poynton et al. 1995, Sterud \& Poynton 2002). 


\section{RESULTS}

Numerous diplomonad trophozoites were found in a crypt in the rainbow trout intestine, and in 1 section 19 of 20 flagellates were cut in transverse section (Fig. 1). Detailed examination (see Figs. 1 to 6) showed that the organism previously named Hexamita salmonis belongs to the genus Spironucleus, and thus we propose to rename it $S$. salmonis n. comb.

\section{Identification to genus}

The 2 nuclei were elongate, tapered anteriorly, and at their apex were entwined in an S-shape (Figs. 2a,b \& 3b). A nucleolus was observed in each nucleus (Fig. 2c). Close to the apex of the entwined nuclei, in an anterior-medial position, lay the 2 clusters of kinetosomes (Fig. 2a,b). Each cluster comprised kinetosomes of 3 anterior flagella (k1, k2, k3) and a kinetosome of 1 recurrent flagellum (kr) (Fig. 2b), with k1, k3, and kr in the same plane (Fig. 3a). Kinetosomes k3 and kr made a pair, and were close to each other (Fig. 3a). There was a right angle between $\mathrm{k} 1$ and $\mathrm{kr}$, and $\mathrm{k} 3$ lay in between at an angle of $45^{\circ}$ to both (Fig. 3a). The 2 recurrent flagella lay between the 2 nuclei (Fig. 2c). Each recurrent flagellum was surrounded by a flagellar pocket (Fig. 2a,c) which arose from a posterior invagination of the cell membrane (see Fig. 5a).

\section{Identification to species}

\section{Cytoskeleton}

There were 3 bands of microtubules present, 2 of these, along with a striated lamina, accompanied the recurrent flagella through the body. Supra-nuclear microtubular bands extended over the anterior of the nuclei, closely following the nuclear membranes (Fig. 2a,b). Direct microtubules originated near the $\mathrm{kr}$, and followed the recurrent flagella (Figs. 2a,c \& 4b,c). Infra-nuclear microtubules had a similar origin, and then crossed over below the nuclei and turned posteriorly to follow the recurrent flagella (Figs. 2a-c \& 4b,c).

In the opening of the striated lamina, microtubular bands lay in a tri-radiate pattern when viewed in transverse section through the middle of the cell (Fig. 4). A more anterior section showed that these bands originated as direct and infra-nuclear microtubular bands (Fig. 2c). The radiate pattern comprised a row of 3 to 5 microtubules concentric around the edge of the flagellar pocket and extending across the open part of the striated lamina (direct band), a straight row of 3 microtubules radiating away from the flagella (direct band), and a slightly curved row of 4 to 5 microtubules extending over the distended side of the striated lamina (infra-nuclear band) (observations from 4 trophozoites) (Fig. 4b,c). Below the latter band, a single microtubule was present in some trophozoites (Fig. 4b). The pattern of the microtubular bands changed posteriorly, with 3 bands reducing to 2, comprising a long band (8 to 10 microtubules) following the edge of the flagellar pocket and extending across the opening of the lamina and under 1 side, and a short band (3 microtubules) extending over the other side of the lamina; the middle band seen in more anterior sections was missing (cf. Figs. 4c \& 5b).

The flagellar pocket was surrounded by an asymmetrical U-shaped striated lamina when viewed in transverse section (Figs. 2c \& 4b,c). Towards the posterior of the cell, the lamina expanded bilaterally, forming a kidney shape in transverse section (Fig. 5c). The diameter of the flagellar pocket increased from anterior to posterior (via uni-lateral dilation) (cf. Figs. 2c \& 5b).

Electron-dense plaques were present in at least 3 locations in the anterior of the trophozoite. Thin plaques lay along cup-shaped depressions of the nuclear membrane, adjacent to the base of the kinetosomes (Fig. 3a,c,d). Plaques were also found near the sides of the anterior kinetosomes and basal portions of the flagella (Fig. 3b,c) and just posterior to the kinetosome of the recurrent flagella, between the axoneme and the striated lamina (Fig. 3b,d).

\section{Cytoplasm}

The cytoplasm of the flagellates comprised 3 distinct regions: (1) a light-staining homogenous region in the apex (Figs. 2a,b \& 3a,b); (2) the organelle-rich heterogenous cytoplasm in most of the remainder of the cell (Figs. 2a, 4a \& 5a); and (3) the sac of densely packed free ribosomes at the posterior of the cell (Figs. 5a,b \& 6a).

The heterogenous cytoplasm which occupied most of the cell contained scattered electron-dense bodies (Figs. 2a,c \& 4a), numerous free ribosomes (Figs. 2c, 4a, $5 \mathrm{a} \& 6 \mathrm{a})$, flocculent regions containing aggregations of glycogen (Figs. 4a, 5a \& 6a), vacuoles, some of which were discharging (Figs. 3c,d \& 6a,d), bowl-shaped membranous structures (Figs. 3c,d, 4a \& 6b,c), and irregularly distributed rough endoplasmic reticulum (Figs. 2a \& 4a).

The membrane-bound electron-dense bodies were usually circular in section, and reached approximately $0.4 \mu \mathrm{m}$ in diameter (Fig. 4a). Occasionally an elongate electron-dense body was seen (Fig. 2c), suggesting that it was discharging its contents into the cytoplasm, or possibly dividing. Some vacuoles were observed discharging their contents through the surface cell membrane (Figs. 3c,d \& 6d). The bowl-shaped mem- 
branous structures appeared as single dilated membranous cisternae with distended ends, and reached approximately $0.25 \mu \mathrm{m}$ in diameter (Fig. 6b,c).

The posterior sac of densely packed free ribosomes was delineated by rough endoplasmic reticulum
(Figs. 5a,b \& 6a). In longitudinal section the sac was pyriform, and in transverse section 2 furrows were seen, which gave the structure an '8-shape' (Fig. 5b). This region appeared to contain only free ribosomes; flocculent regions containing aggregations of glycogen

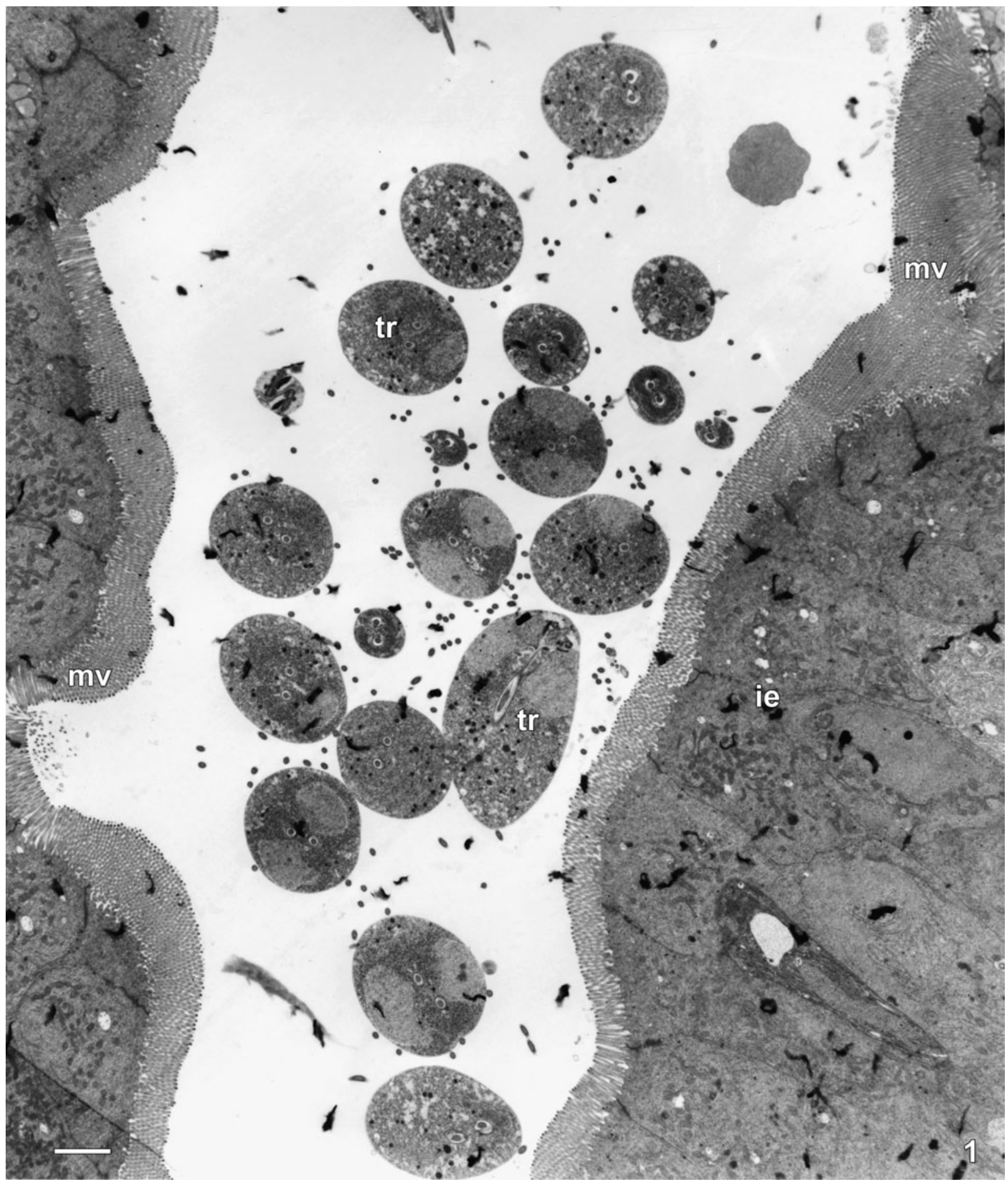

Fig. 1. Spironucleus salmonis n. comb. infecting Oncorhynchus mykiss. Transmission electron micrograph of 20 diplomonad flagellates in a crypt in intestine of fingerling rainbow trout from Northern Ireland. Note that most of the trophozoites (tr) are cut in transverse section. Contact with the host's intestinal epithelium (ie) via microvilli (mv) is not evident. (Scale bar $=5 \mu \mathrm{m}$ ) 

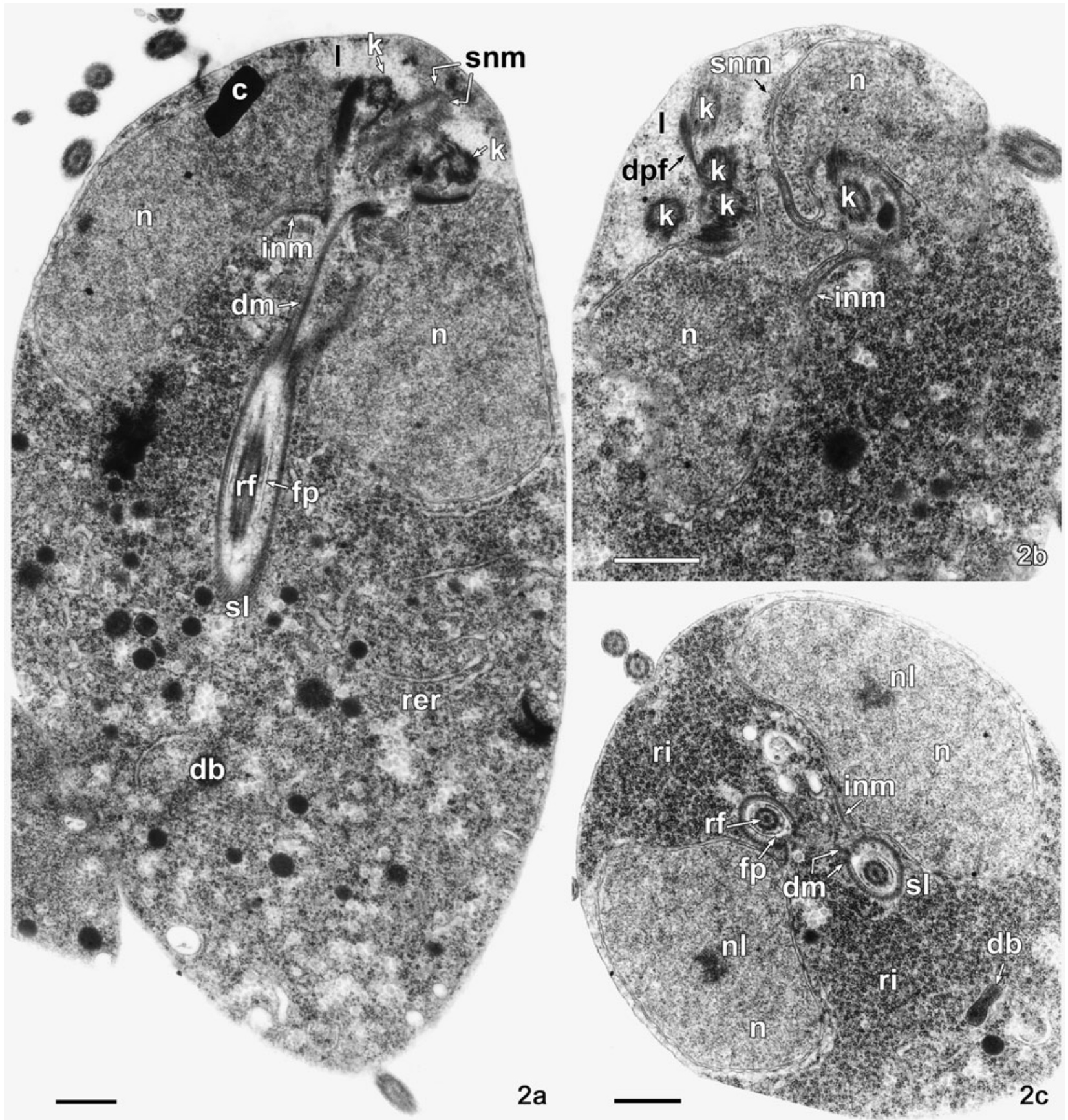

Fig. 2. Spironucleus salmonis n. comb. infecting Oncorhynchus mykiss. Transmission electron micrographs of diplomonad flagellates in intestine of fingerling rainbow trout from Northern Ireland, showing features for identification to genus: elongate nuclei (n) are S-shaped and wrapped around each other apically; kinetosomes (k) are anterio-medial; flagellar pocket (fp) is present; and recurrent flagella (rf) pass posteriorly between the nuclei. (a) Longitudinal section through cell; note supra-nuclear microtubules (snm), infra-nuclear microtubules (inm), direct microtubules (dm), striated lamina (sl) accompanying recurrent flagellum (rf) and flagellar pocket (fp), apical light-staining homogenous cytoplasm (l), scattered electron-dense bodies (db) and rough endoplasmic reticulum (rer); angular electron-dense material is contamination (c). (Scale bar $=0.5 \mu \mathrm{m}$ ). (b) Oblique section through anterior of cell; note electron-dense plaque (dpf) adjacent to kinetosomes (k), supra-nuclear microtubules (snm), infranuclear microtubules (inm) and apical light-staining homogenous cytoplasm (l). (Scale bar $=0.5 \mu$ m). (c) Transverse section through anterior of cell (more posterior than in b); note that nuclei (n) contain nucleoli (nl); band of infra-nuclear microtubules (inm) passes from medial surface of a nucleus to accompany the recurrent flagellum (rf) adjacent to opening of the striated lamina (sl) at distended side next to the nucleus; band of direct microtubules (dm) spans opening of the striated lamina (sl); 1 electrondense body $(\mathrm{db})$ is elongate (arrowed), possibly discharging its contents into cytoplasm of the cell; numerous free ribosomes (ri) are present throughout cytoplasm. (Scale bar $=0.5 \mu \mathrm{m}$ ) 

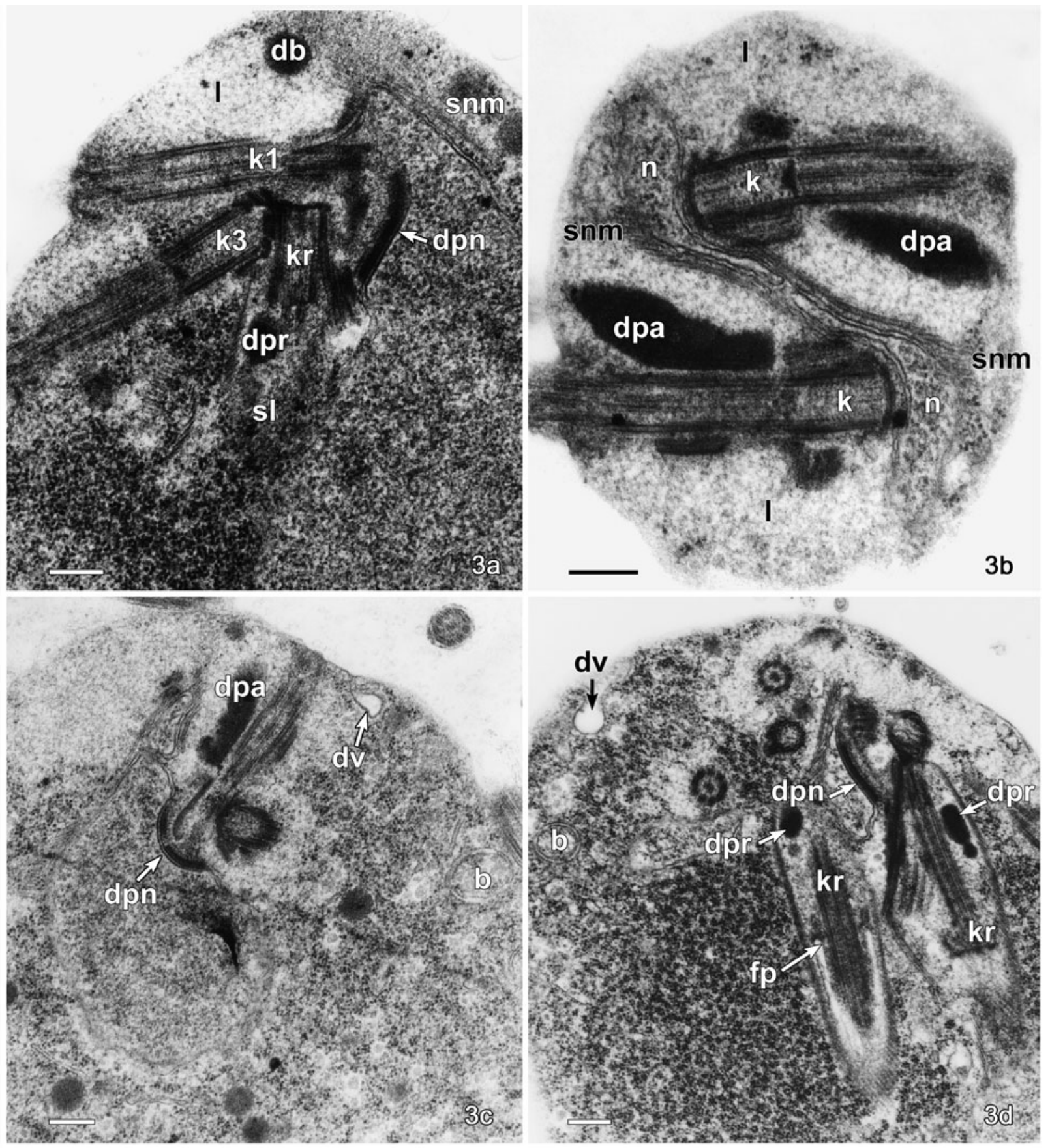

Fig. 3. Spironucleus salmonis n. comb. infecting Oncorhynchus mykiss. Transmission electron micrographs of diplomonad flagellates in intestine of fingerling rainbow trout from Northern Ireland, showing anterior of cell with kinetosomes. (a) Longitudinal section through kinetosomes k1, k3, and kr below apical light-staining homogenous cytoplasm (l); electron-dense plaque (dpn) lies against cup-shaped depression of nuclear membrane close to the kinetosomes; electron-dense plaque (dpr) lies just posterior to kinetosome $\mathrm{kr}$ between axoneme and striated lamina (sl); electron-dense body (db) and supra-nuclear microtubules $(\mathrm{snm})$ can be seen at apex of cell. (Scale bar $=0.25 \mu \mathrm{m})$. (b) Transverse section through apex of cell, showing 2 anterior kinetosomes (k), 1 from each karyomastigont, each of which is accompanied by a medial electron-dense plaque (dpa) and some other less electron-dense regions; apices of nuclei (n), and their supra-nuclear microtubules (snm) demonstrate rotational symmetry of the cell. (Scale bar $=0.25 \mu \mathrm{m}$ ). (c) Oblique section through anterior of cell, showing electron-dense plaques against depression of nucleus (dpn) and accompanying anterior flagella (dpa); recently discharged vacuole (dv) lies just beneath cell membrane; bowlshaped membranous structure (b) is shown in transverse section. (Scale bar $=0.25 \mu \mathrm{m}$ ). (d) Oblique section through anterior of cell; recurrent flagella are cut in longitudinal section and their electron-dense plaques (dpr) can be seen; top of flagella pocket (fp, arrow) is visible on left; a recently discharged vacuole (dv) lies just beneath cell membrane; a bowl-shaped membranous structure (b) is shown in transverse section. (Scale bar $=0.25 \mu \mathrm{m}$ ) 

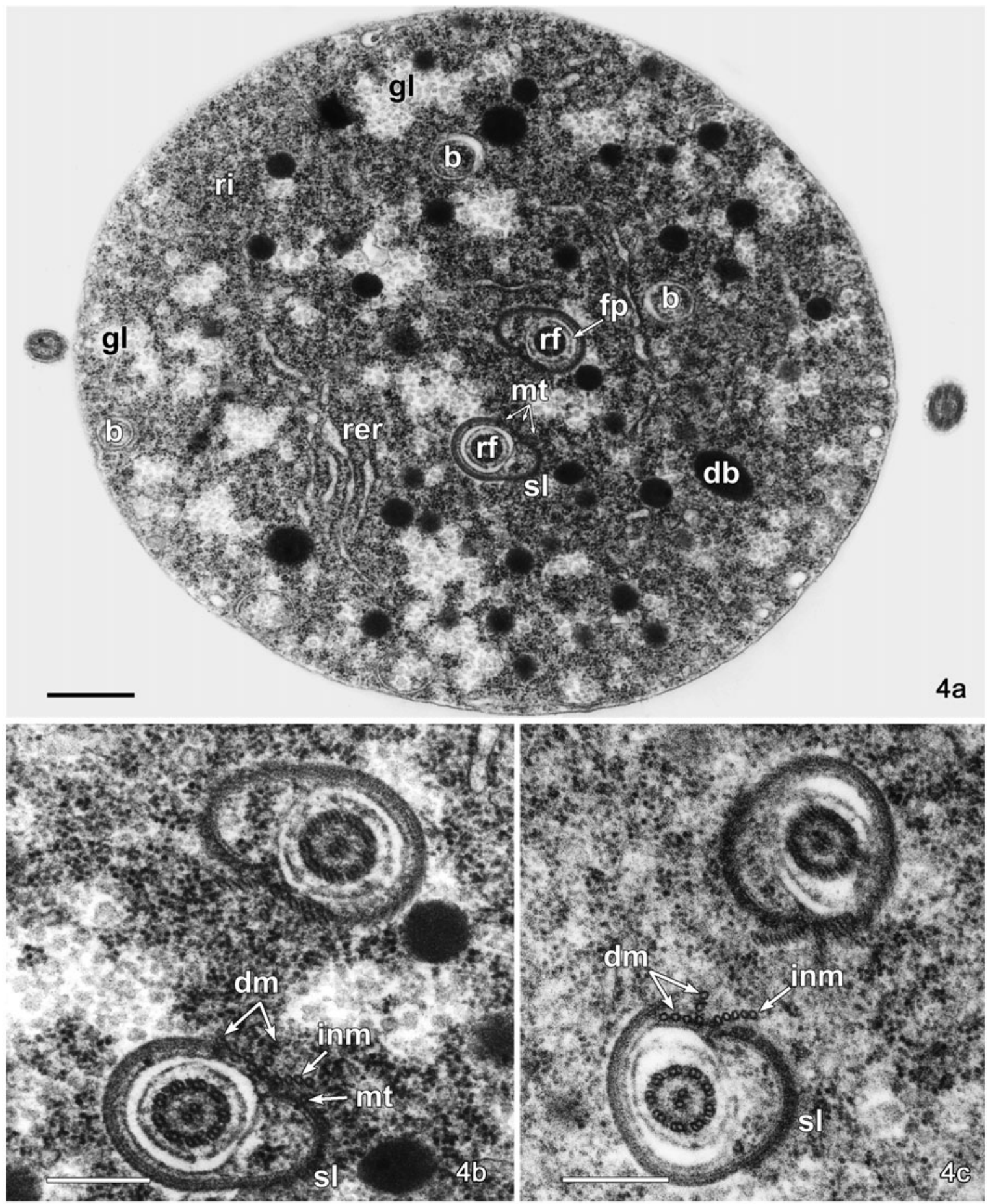

Fig. 4. Spironucleus salmonis n. comb. infecting Oncorhynchus mykiss. Transmission electron micrographs of diplomonad flagellates in intestine of fingerling rainbow trout from Northern Ireland, showing microtubules accompanying recurrent flagella for identification to species. (a) Two recurrent flagella (rf) within flagellar pockets (fp) pass through middle of cell, accompanied by bands of microtubules (mt) and asymmetric striated lamina (sl); rough endoplasmic reticulum (rer), electron-dense bodies (db), bowl-shaped membraneous structures (b), numerous free ribosomes (ri) and flocculent regions containing aggregates of glycogen (gl) are scattered throughout cytoplasm. (Scale bar $=0.5 \mu \mathrm{m})$. (b,c) The 3 microtubular bands radiate at opening of the asymmetrical striated lamina (sl); radiate pattern comprises (from left to right in these micrographs) a row of 3 to 5 microtubules extending from tip of striated lamina across opening of the striated lamina, closely following edge of the flagellar pocket (direct) $(\mathrm{dm})$, a straight row of 3 microtubules radiating away from opening of the striated lamina (direct) (dm), and a slightly curved row of 4 to 5 microtubules extending over distended side of the striated lamina (infra-nuclear microtubules) (inm); below latter band may lie a single microtubule (mt). (b) is an enlargement of (a). (Scale bars $=0.25 \mu \mathrm{m}$ ) 

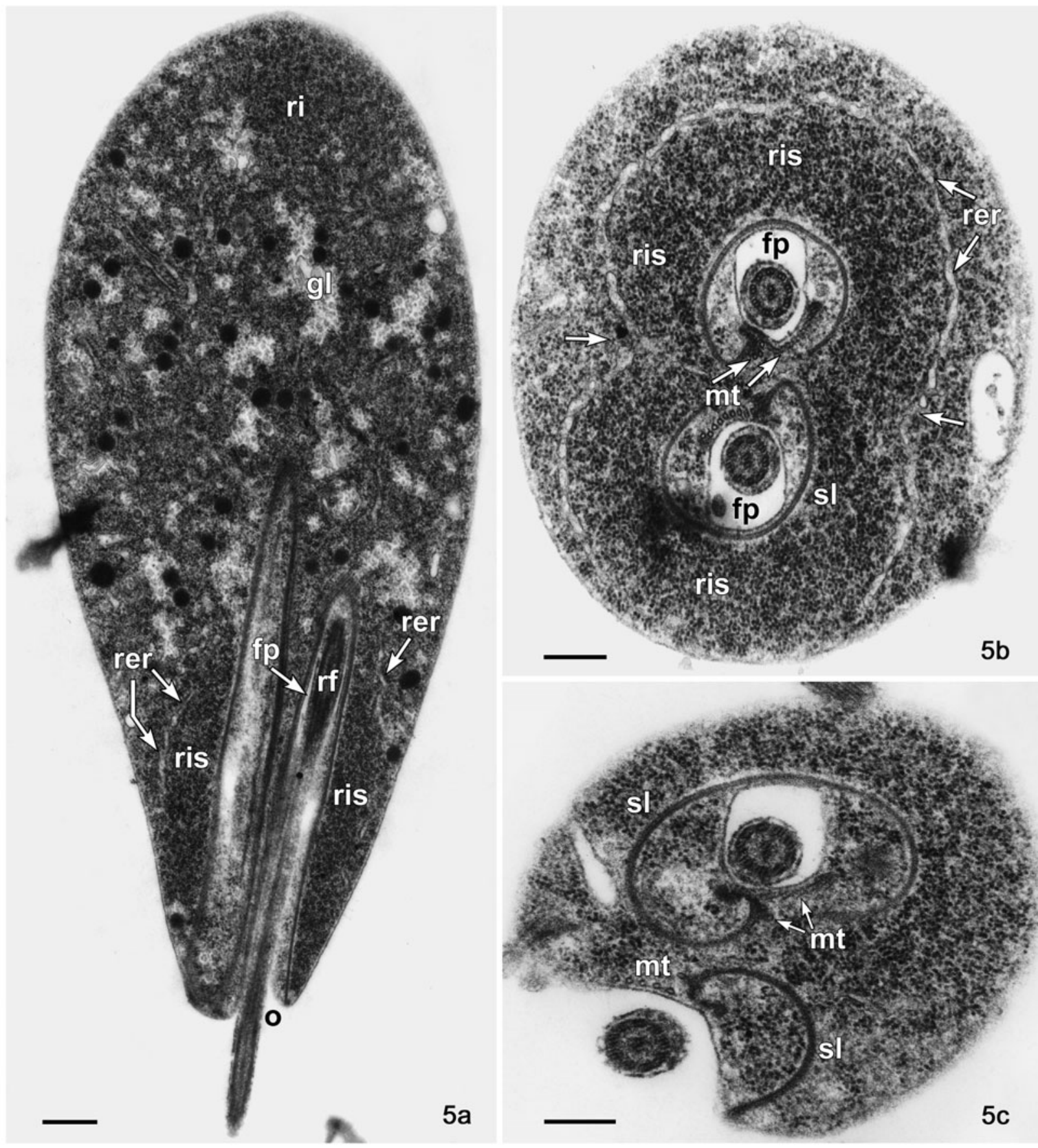

Fig. 5. Spironucleus salmonis n. comb. infecting Oncorhynchus mykiss. Transmission electron micrographs of diplomonad flagellates in intestine of fingerling rainbow trout from Northern Ireland, showing sac of densely packed ribosomes at posterior of cell for identification to species. (a) Longitudinal section through posterior of cell, showing terminal pyriform region of densely packed free ribosomes (ris) limited by rough endoplasmic reticulum (rer) through which pass emerging recurrent flagella (rf); flocculent regions containing of glycogen ( $\mathrm{gl}$ ) and free ribosomes (ri) are present in remainder of the cytoplasm; opening (o) of flagellar pocket (fp) is formed by invagination of the cell membrane. (Scale bar $=0.5 \mu \mathrm{m}$ ). (b) Transverse section through posterior end of cell, showing densely packed free ribosomes (ris) limited by bi-furrowed (arrows) sac of rough endoplasmic reticulum (rer), which is '8-shaped' in transverse section; within this region lie the recurrent flagella, each of which is accompanied by 2 bands of microtubules (mt); a longer band of approximately 8 to 10 microtubules passing under one end of striated lamina (sl) and closely following edge of the flagellar pocket (fp) to reach across the opening of the bilaterally expanded striated lamina, and a shorter band of 3 microtubules then extending over end of the striated lamina. (Scale bar $=0.25 \mu \mathrm{m}$ ). (c) Transverse section through extreme posterior end of cell, showing 1 emerging and 1 emerged flagellum; around emerging flagellum are microtubules (mt) across opening of the striated lamina (sl) and adjacent to its end; the striated lamina is greatly expanded into a kidney shape; close to angular cell surface near the emerged flagellum, 6 clearly separated microtubules lie just beneath cell membrane and striated lamina forms an adjacent semi-circle. (Scale bar $=0.25 \mu \mathrm{m}$ ) 
were not seen. The posteriormost regions of the recurrent flagella, and their associated microtubular bands and striated lamina, passed through the sac of free ribosomes; flagella emerged close together through the posterior end of the cell (Fig. 5).

Mitochondria, Golgi apparatus, and bacteria were not apparent in the cytoplasm.

\section{Deposition of type material}

A TEM grid, originally studied by Ferguson (1979) and re-examined in the present study, has been deposited at the International Protozoan Type Slide Collection at the Department of Invertebrate Zoology, National Museum of Natural History, Smithsonian Institution, Washington,

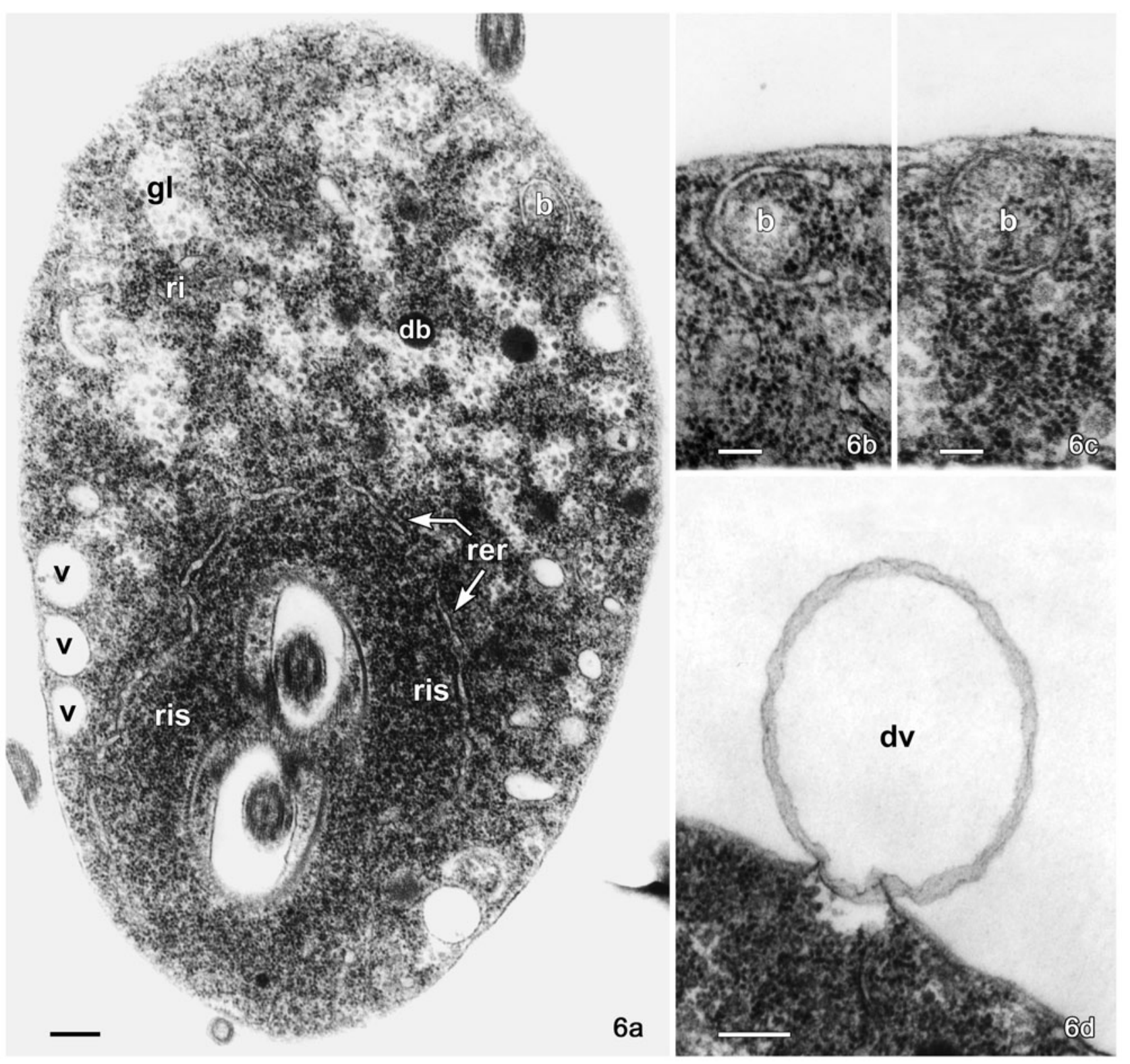

Fig. 6. Spironucleus salmonis n. comb. infecting Oncorhynchus mykiss. Transmission electron micrographs of diplomonad flagellates in intestine of fingerling rainbow trout from Northern Ireland, showing cytoplasmic organelles for identification to species. (a) Oblique section through posterior end of cell, showing sac of dense free ribosomes (ris) limited by rough endoplasmic reticulum (rer); remaining heterogenous cytoplasm contains electron-dense bodies (db), vacuoles (v), free ribosomes (ri), flocculent regions containing aggregates of glycogen (gl), and bowl-shaped membraneous structures (b). (Scale bar $=0.25 \mu \mathrm{m}$ ). (b,c) Transverse sections through middle of cell, showing details of bowl-shaped membraneous structures (b), which are cut in longitudinal section in panel (b) and in transverse section in panel (c). (Scale bars $=0.125 \mu \mathrm{m}$ ). (d) Longitudinal section through middle of cell, showing vacuole discharging $(\mathrm{dv})$ through cell membrane into external milieux of lumen contents. (Scale bar $=0.25 \mu \mathrm{m})$ 
DC 20506, USA (see also: cole.linda@nmnh.si.edu, www.nmnh.si.edu/sysbiology). The accession number is 1024945 .

\section{DISCUSSION}

Ultrastructural examination of the pathogenic diplomonad from the intestine of rainbow trout shows that Hexamita salmonis (as reported by Ferguson 1979), should be reassigned to the genus Spironucleus. We therefore propose to rename this diplomonad Spironucleus salmonis. Our studies have provided comprehensive characterisation of this species, with particular emphasis on cytoskeletal and cytoplasmic features of the trophozoites. By comparison with studies on other well-characterised diplomonads from fishes, we have produced a diagnostic guide for identification to species (see Table 1).

Review of the morphology of Octomitus salmonis as illustrated by Moore $(1922 \mathrm{a}, \mathrm{b})$ and Davis (1926) showed that this organism also belongs to the genus Spironucleus. We synonymise Hexamita salmonis sensu Ferguson (1979) with Octomitus salmonis sensu Moore (1922a,b) and Davis (1926), and rename them Spironucleus salmonis.

\section{Determination of genus}

New assignment of Hexamita salmonis (Ferguson 1979) to the genus Spironucleus was made based on the shape of the nuclei (elongate, tapering and intertwined anteriorly), location of the kinetosomes (anterior-medial), and presence of a flagellar pocket (according to the recently published guidelines for descriptions of diplomonads from fishes; Poynton \& Sterud 2002).

The proposed reassignment of Hexamita salmonis (as described by Ferguson 1979) to Spironucleus salmonis helps to resolve a long-standing taxonomic dilemma. Even within the last decade, the debate has continued, with the possibility of removing H. salmonis from the genus Hexamita being raised by Kent et al. (1992), and its 'probable' reassignment to Spironucleus suggested by Sterud et al. (1997). Our reassignment supports the contention of Poynton \& Sterud (2002) that all diplomonads from fishes belong to the genus Spironucleus. This finding may have practical implications for fish health, since Siddall et al. (1992) suggest that Spironucleus is more highly evolved to parasitism than is Hexamita, and can maintain a position on the intestinal epithelium and also invade the mucosa and localise in other tissues, which Hexamita cannot.

\section{Comparison of Spironucleus salmonis with other diplomonads from fishes}

We compared the newly elucidated cytoskeletal and cytoplasmic features of Spironucleus salmonis with those of the 3 species of diplomonad from fishes for which the ultrastructure is known, namely $S$. barkhanus, $S$. torosa, and $S$. vortens, and which can thus be regarded as well-characterised (Poynton \& Morrison 1990, Poynton et al. 1995, Sterud et al. 1997, 1998, Sterud 1998a,c). We also compared S. salmonis with the early descriptions of Octomitus salmonis, in order to determine their possible synonymy (Hexamita salmonis has often been assumed to be a synonym of O. salmonis) (see 'Synonymy of Octomitus salmonis with Hexamita salmonis and renaming as Spironucleus salmonis' below). We have not attempted to compare $S$. salmonis with all other diplomonads from fishes that have been described by light microscopy only, since this technique is insufficient to characterise species.

Spironucleus salmonis is clearly distinguished from both $S$. torosa and $S$. vortens by surface ornamentation and its supporting cytoskeleton (absent in the former, tori in $S$. torosa, compound lateral ridges countercrossing at the posterior end in S. vortens), and the cross-section pattern of microtubules accompanying the flagellar pocket (3 radiate in $S$. salmonis, 3 concentric in $S$. torosa, and 3 staggered in $S$. vortens). $S$. salmonis is further distinguished from $S$. torosa and $S$. vortens by cytoplasmic features, since the electrondense bodies, posterior sac of densely packed free ribosomes and bowl-shaped structures all occur in $S$. salmonis but not in $S$. torosa or $S$. vortens. Dense plaques associated with kinetosomes, as we now describe for $S$. salmonis, are also present in $S$. vortens. Furthermore, in S. salmonis, we did not observe superficial or cytoplasmic bacteria whereas these are known for S. torosa (Poynton \& Morrison 1990, Sterud 1998c) (we do not know if bacteria are also intimately associated with $S$. vortens, since ultrastructure of this species is only known for cultured organisms).

Distinguishing Spironucleus salmonis from S. barkhanus is difficult, and there are numerous similarities between the 2 species. Although we were unable to study the surface architecture of S. salmonis, the TEM sections indicate that the body is unadorned, similar to $S$. barkhanus. Both species have a 3 radiate pattern of microtubules accompanying the recurrent flagella, but there are some subtle differences in (1) location of the convergence of the bands in the opening of the striated lamina, (2) placement of 1 of the bands of direct microtubules, and (3) number of microtubules per band (cf. Fig. $4 \mathrm{a}$, b in the present paper, with Fig. 6c in Sterud et al. 1997 and Fig. 5b in Sterud et al. 1998). In S. salmonis, there is no space between the convergence of the 
bands, whereas in S. barkhanus there is a space of approximately 1 microtubule width between the convergence of the bands. In S. salmonis, the band of direct microtubules that passes concentrically around the flagellar pocket across the opening of the striated lamina does so at, or below, the end of the striated lamina, whereas in $S$. barkhanus the corresponding band radiates above the end of the striated lamina. In $S$. salmonis, the maximum number of microtubules in each of the radiating bands was 5, 3, 5 (following the scheme in the legend for Fig. $4 \mathrm{~b}$ and c), in $S$. barkhanus the corresponding numbers were $3,2,6$. In both species, the striated lamina is asymmetrical and expands posteriorly to become kidney shaped. It is not known if electron-dense plaques are associated with the kinetosomes of $S$. barkhanus, since these were not shown in either of the publications by Sterud et al. (1997, 1998).

It is perhaps in the cytoplasm that the differences between Spironucleus salmonis and S. barkhanus are most marked. In $S$. salmonis, the cytoplasm contains electron-dense bodies, numerous free ribosomes, flocculent regions of aggregated glycogen, vacuoles, bowl-shaped structures, scattered endoplasmic reticulum, and the distinctive sac of densely packed free ribosomes at the posterior of the body. In S. barkhanus, the cytoplasm does not contain electron-dense bodies or a posterior sac of densely packed free ribosomes, and the endoplasmic reticulum is abundant around the flagellar pocket, especially in the posterior of the cell. Other cytoplasmic organelles are the same, including the bowl-shaped structures. The structures in S. salmonis that we identify as free ribosomes were identified as granular cytoplasm by Sterud et al. (1997), and that which we identify as aggregated glycogen was illustrated by Sterud et al. (1997) but not named. We distinguished glycogen and clusters of free ribosomes based on differences in staining (glycogen is often not well preserved, appearing hazy), and size (aggregates of glycogen being approximately 10 times larger than clusters of ribsomes) (Bozzola \& Russell 1992, Sandborn 1970). It is possible that the differences in cytoplasmic organelles between $S$. salmonis and $S$. barkhanus could be accounted for by the fact that $S$. salmonis is described from organisms taken directly from the fish hosts, and $S$. barkhanus is described from axenic culture.

Despite the numerous similarities between Spironucleus salmonis and $S$. barkhanus, we believe that the 2 species must, at present, be retained as distinct species, since there are ultrastructural features which appear to distinguish them. To resolve the question of synonymy, 3 ultrastructural aspects must be documented: the surface ultrastructure of $S$. salmonis, presence or absence of electron-dense plaques adjacent to the kinetosomes of $S$. barkhanus, and the cytoplasmic features of $S$. barkhanus taken directly from the host (with particular attention being focused on the possible presence of electron-dense bodies, and a sac of densely packed free ribosomes at the posterior end of the body). If $S$. barkhanus and $S$. salmonis are subsequently shown to be synonymous, $S$. salmonis will have taxonomic priority.

If synonymy between Spironucleus barkhanus and S. salmonis is subsequently established, this will have significant implications for health management of salmonids in aquaculture. S. barkhanus is known as a significant systemic invader in adult Atlantic salmon and probably also in adult coho salmon, whereas $S$. salmonis is known as an intestinal parasite of juvenile rainbow trout. If indeed synonymy is established, this would imply that there may be host-specific pathogenicity within S. salmonis, or strain-specific pathogenicity.

Comprehensive cross-infection trials are clearly needed is order to determine the host range of Spironucleus salmonis, S. barkhanus and the diplomonad from Chinook salmon in Canada. Previous crossinfection studies of diplomonads in salmonids appear to have been limited to parasites taken from juvenile and adult Chinook salmon in North America (Uzmann et al. 1965 and Kent et al. 1992 respectively). We are not aware of any experimental studies using diplomonads from rainbow trout in Europe. Furthermore, comparative ultrastructural studies made during the proposed trials will demonstrate whether the host environment induces changes in the cytoskeleton and/or cytoplasm of the trophozoites. Environment (of medium) is known to induce changes in glycogen metabolism in 2 other species of diplomonad, namely Giardia intestinalis and Hexamita sp. (Cross \& Zalitis 1998).

\section{Functional morphology of Spironucleus salmonis}

The membrane-bound dense bodies in Spironucleus salmonis (usually spherical, occasionally elongate, the latter suggesting discharges of contents or division), could be interpreted as secretory granules or lysosomes, based on their structure. Distinguishing these alternatives is primarily dependent upon identification of their contents, these being secretory products in the former and hydrolytic enzymes in the latter (Bozzola \& Russell 1992). In addition, high-magnification TEM can distinguish primary and secondary lysosomes (the former being smaller and with a homogenous but granular interior, and the latter being larger with a heterogenous interior due to the presence of remnants of ingested material). 
The presence of numerous vacuoles attests to the active metabolism within the heterogenous cytoplasm of Spironucleus salmonis, as is known for other diplomonads from fishes. We observed a vacuole discharging its contents through the surface of the cell, an occurrence that could be anticipated from other studies of diplomonads from fishes, but not previously demonstrated.

The identity and function of the bowl-shaped structures are unknown. We do not consider these bowlshaped structures to be vacuoles, since the material inside them was the same as the remainder of the cytoplasm and thus did not appear to be digested. Furthermore, their profiles were more consistent with that of a bowl-shaped membranous cisternum than of a spherical vacuole. Their appearance is similar to that of a Golgi apparatus, although there is a single cisternum rather than a stack of cisternae; true Golgi are reported to be absent from diplomonads (Brugerolle \& Lee 2002). Similar structures have previously been reported from Spironucleus barkhanus (see Fig. 7 in Sterud et al. 1997), and were considered to be vacuoles.

The sac of densely packed free ribosomes, bound by furrowed endoplasmic reticulum, at the posterior end of the body of Spironucleus salmonis has not previously been reported. The function of this distinct region is unknown, although from its structure we speculate that it is specialised for polypeptide synthesis.

Although we did not find any Spironucleus salmonis trophozoites attached to the intestinal epithelium, the finding that 19 of 20 trophozoites were cut in transverse section could be accounted for by these being attached organisms, with the parasite/host interface being out of the plane of section (cf. Fig. 1 of this paper with Fig. 25a of Poynton \& Morrison 1990). Davis (1926) noted that the anterior end of Octomitus salmonis 'is very mobile and changes shape rapidly, sometimes being thrust out... and again retracted'; and speculated that this may be a modification for attachment to, and possibly penetration into, host tissues (a similar anterior region was also noted by Schmidt 1919/1920). If attachment is indeed present in $S$. salmonis, we presume that this serves for nutrition, as was suggested for $S$. torosa, which attaches to the rectal microvilli in its gadid hosts (see Fig. 25a,c,d in Poynton \& Morrison 1990).

\section{Synonymy of Octomitus salmonis with Hexamita salmonis, and renaming as Spironucleus salmonis}

In Moore's original descriptions (1922a,b) (smears stained with iron-hematoyxlin or Delafield and eosin from American brook trout), and Davis' redescription (1926) (hematoxylin-stained smears) of Octomitus salmonis, tapering nuclei and anterior-medial kinetosomes were also shown, but the presence or absence of a flagellar pocket was not determined. Although we now recognise these former 2 features as being characteristic of Spironucleus, this genus was not available to Moore $(1922 \mathrm{a}, \mathrm{b})$ or Davis $(1926)$, since it was not erected until 1936 by Lavier (with the type species Spironucleus elegans described from amphibians).

Comparison of the ultrastructural features of Spironucleus salmonis described herein with those elucidated by light microscopy in the original descriptions of Octomitus salmonis (Moore 1922a,b, Davis 1926) raises an interesting question concerning the posterior end of the body. We have shown that this region contains a furrowed sac of densely packed free ribosomes through which the recurrent flagella-and their associated expanded striated lamina-pass. Moore $(1922 \mathrm{a}, \mathrm{b})$ illustrated broadening stained regions at the posterior of the flagellar pockets, which she described as grooves. Davis (1926) reported that the structure consisted of 3 or 4 chromatic bands extending about one-third of the length of the recurrent flagella, which form 'a pair of funnel-shaped structures attached to the axostyles, with the smaller end pointed forward', which are 8-shaped in posterior/transverse view. Our ultrastructural studies did not show grooves at the posterior end of the body, and we therefore suggest that these posterior chromatic regions from the early descriptions could be cytoskeletal or cytoplasmic features representing the expanded striated lamina or the endoplasmic reticulum-bound sac of free ribosomes. We consider the former to be the most likely. For comparative purposes, new samples of the diplomonads would need to be collected from the Northern Irish rainbow trout applying the same staining protocols as used by Moore $(1922 \mathrm{a}, \mathrm{b})$ and Davis (1926).

There is evidence that Octomitus salmonis sensu Moore (1922a,b) and Davis (1926) is the same organism as Hexamita salmonis sensu Ferguson (1979): both organisms are clearly Spironucleus; cytoskeletal features appeared consistent; the pathology associated with infections reported for $O$. salmonis by Moore (1922a,b) and Davis (1926) and for H. salmonis by Ferguson (1979) were similar, namely mortality among rainbow trout fry with intestinal infections. Furthermore, Ferguson (1979) clearly considered that the organism he studied was the same as that earlier described as O. salmonis by Moore $(1922 \mathrm{a}, \mathrm{b})$. We therefore synonymise $O$. salmonis sensu Moore (1922a,b) and sensu Davis (1926) with H. salmonis sensu Ferguson (1979), and rename both of them $S$. salmonis. 


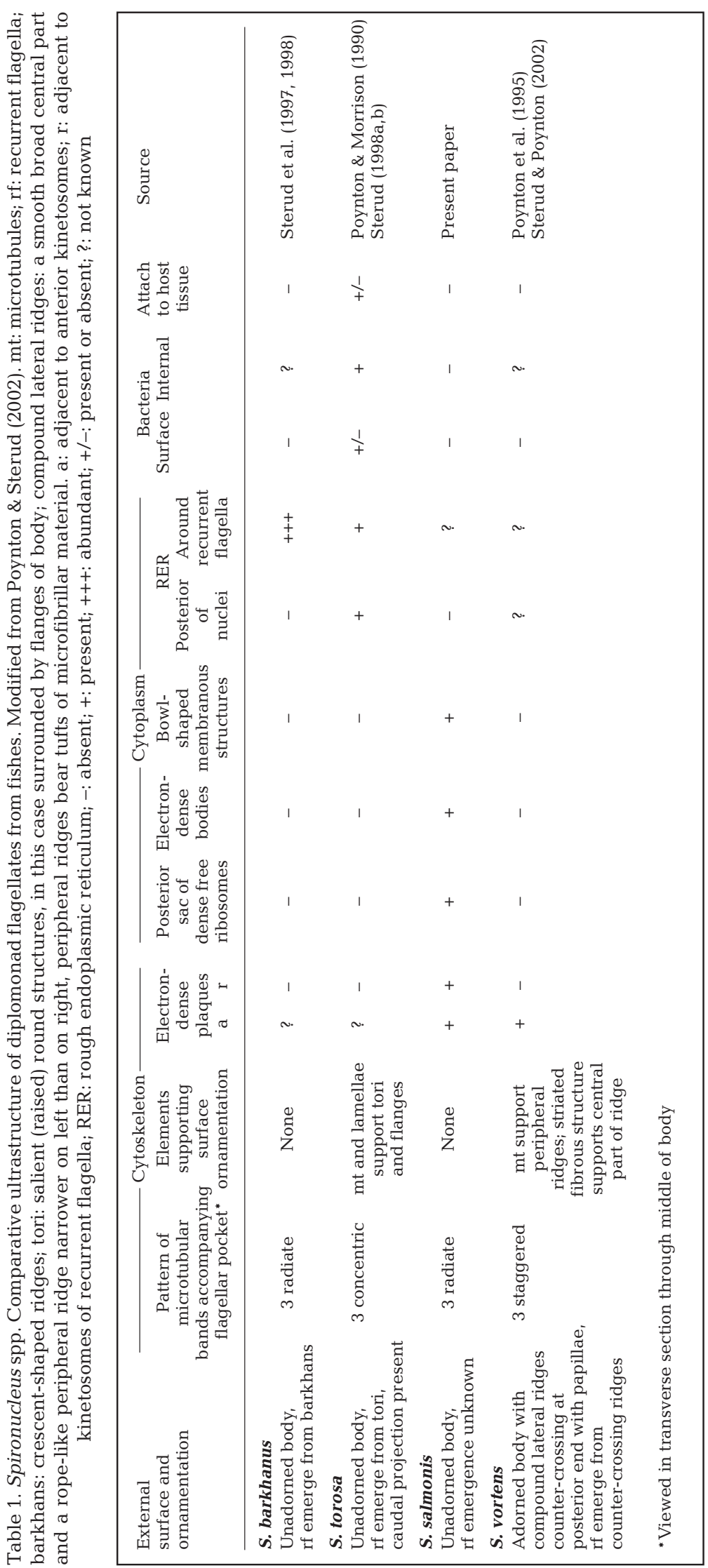

However, we wish to emphasise that the present paper only synonymises Octomitus salmonis sensu Moore $(1922 \mathrm{a}, \mathrm{b})$ and sensu Davis (1926) with Hexamita salmonis sensu Ferguson (1979). We cannot determine which other organisms reported in the literature as $\mathrm{O}$. salmonis or $\mathrm{H}$. salmonis are the organism we now describe as Spironucleus salmonis. In the absence of morphological and ultrastructural studies, which are lacking in most literature, genus and species of diplomonads cannot be determined with certainty.

\section{Diagnostic guide for recognition of diplomonad species from fishes}

At present, ultrastructure is the only reliable technique by which species of diplomonads from fishes can be distinguished, and although it is unlikely to be used for routine screening and diagnosis, ultrastructure is of critical importance in clinical situations. With this in mind, we now offer a new comprehensive table for the recognition of diplomonad species from fishes (Table 1). The present study extends the comparative ultrastructural information provided by Poynton \& Sterud (2002) by inclusion of inferred surface features and observed cytoskeletal features for Spironucleus salmonis. We also include cytoplasmic features for the 4 species of diplomonads from fishes, since these appear to hold taxonomic value; however, in this respect, comparisons between species must be approached with caution since some desciptions derive from flagellates from the fishes while others are from in vitro culture.

\section{Development of new species-specific diagnostic tests}

The unique combination of cytoskeletal and cytoplasmic features of diplomonads from fishes that have been elucidated by ultrastructural studies can indicate structures and organelles that could be targeted for species-specific light-microscopy diagnostic tests. Previously, such tests have been limited to the use of protargol silver protein to demonstrate micro- 
tubular and fibrillar structures, such as the tori of Spironucleus torosa and the counter-crossing ridges of S. vortens (Poynton \& Morrison 1990, Poynton et al. 1995). The apparent absence of surface ornamentation in $S$. salmonis suggests that no special features would be shown in protargol impregnated smears, and thus $S$. salmonis could be differentiated from $S$. torosa and S. vortens.

The electron-dense bodies and the sac of densely packed free ribsomes in Spironucleus salmonis appear to be unique to this species, and are therefore considered to be suitable targets for species-specific diagnostic tests, which we are currently developing. Identification of species-specific suites of cytoplasmic organelles, suggested to be related to the production of different enzymes by each species, has previously been reported for other common fish parasites, namely myxosporidians (Stehr \& Whitaker 1986).

Although the possibility exists of environmentally induced changes in cytoplasmic organelles, we nonetheless believe that cytoplasmic organelles have diagnostic value. Since species-specific diagnostic tests will most frequently be used by diagnostic laboratories, diplomonad samples will be taken directly from the fishes, and thus changes induced by in vitro culture conditions will not be encountered.

\section{Recommendations}

Ultrastructural studies, following the guidelines of Poynton \& Sterud (2002), are needed on diplomonads from the digestive tract of rainbow trout and other salmonids from diverse geographic localities. Such studies will establish the true identity of the parasite(s), and if they are also found to be Spironucleus salmonis, then the geographic range of this parasite can be recorded.

To resolve some of the remaining questions about identification, ecology and pathogenicity of diplomonads from salmonids, further ultrastructural and crossinfection studies are needed (as detailed in the earlier subsection 'Comparison of Spironucleus salmonis with other diplomonads from fishes'). We also recommend that future type descriptions and redescriptions be made from material taken directly from the fish hosts, thereby enabling the original cytoplasmic features and the presence of superficial or cytoplasmic bacteria to be used as taxonomic characters.

Molecular taxonomy and protein-code sequencing of diplomonads from fishes also hold promise. However, such an approach is still in its infancy for these parasites, in part because of the paucity of species which are well recognised and which have been isolated and maintained in vitro (Poynton \& Sterud 2002). Sequenc- ing has been achieved for 3 diplomonads from fishes: Spironucleus barkhanus, S. vortens, and an unidentified diplomonad from Chinook salmon by Keeling \& Doolittle $(1996,1997)$. We recommend the addition of S. salmonis to this list, with a view to developing species-specific molecular probes.

Accurate identification of diplomonads is essential to support epizootiological studies, which we expect to play an increasingly important role in management of these pathogenic infections, particularly in countries where effective treatments such as metronidazole and its derivatives are not permitted for use in aquaculture.

Acknowledgements. Dr. David Johnson (Natural History Museum, London) and Dr. Clive Bennett (University of Southampton) are most warmly thanked for inspiring this study. Colonel William Inskeep (Department of Veterinary Pathology, Armed Forces Institute of Pathology, Washington), graciously provided facilities for our ultrastructure studies. Ms. Ellen Winslow (Pathology Photography and Graphics, Johns Hopkins University School of Medicine, Baltimore) carefully prepared the photograph plates. Our colleague Dr. Klaus Knopf (Institute for Freshwater Ecology and Inland Fisheries, Berlin) provided most helpful comments on an initial draft of this paper. We gratefully acknowledge the Deutsche Forschungsgemeinschaft for the award of a Mercator Visiting Professorship to S.L.P.

\section{LITERATURE CITED}

Allison LN (1963) An unusual case of Hexamita (Octomitus) among yearling rainbow trout. Prog Fish-Cult 25:220-222

Awakura T (1992) Parasites of salmonid fishes in Japan. In: Kimura T (ed) Salmonid diseases (Proceedings of the OJI International Symposium on Salmonid Diseases). Hokkaido University Press, Sapporo, p 259-266

Bozzola JJ, Russell LD (1992) Electron microscopy, principles and techniques for biologists. Jones \& Bartlett, Boston

Brugerolle G (1974) Contribution a l'étude cytologique et phylétique des diplozoaires (Zoomastigophorea, Diplozoa; Dangeard 1910). III. Étude ultrastructurale du genre Hexamita (Dujardin 1836). Protistologica 10:83-90

Brugerolle G (1975) Contribution a l'étude cytologique et phylétique des diplozoaires (Zoomastigophorea, Diplozoa; Dangeard 1910). V. Caracteres généraux des diplozoaires. Protistologica 11:111-118

Brugerolle G, Lee JJ (2002) Order Diplomonadida. In: Lee JJ, Leedale GF, Bradbury P (eds) An illustrated guide to the Protozoa, 2nd edn. Society of Protozoologists, Lawrence, KS, p 1125-1135

Brugerolle G, Joyon L, Oktem N (1973) Contribution a l'étude cytologique et phylétique des diplozoaires (Zoomastigophorea, Diplozoa; Dangeard 1910). II. Étude ultrastructurale du genre Spironucleus (Lavier 1936). Protistologica 9:495-502

Brugerolle G, Joyon L, Oktem N (1974) Contribution a l'étude cytologique et phylétique des diplozoaires (Zoomastigophorea, Diplozoa; Dangeard 1910). IV. Étude ultrastructurale du genre Octomitus (Prowazek 1904). Protistologica 10:457-463 
Cross DS, Zalitis JG (1998) Interaction of fuels in diplomonads, Giardia and Hexamita on growth and glycogen levels. J Eukaryot Microbiol 46 (Suppl 8A)

Davis HS (1926) Octomitus salmonis, a parasitic flagellate of trout. Bull Bur Fish Wash 42:9-26

Ferguson HW (1979) Scanning and transmission electron microscopical observation on Hexamita salmonis (Moore, 1922) related to mortalities in rainbow trout fry Salmo gairdneri Richardson. J Fish Dis 2:57-67

Hare GM, Frantsi C (1974) Abundance and potential pathology of parasites infecting salmonids in Canadian Maritime hatcheries. J Fish Res Board Can 31:1031-1036

Keeling PJ, Doolittle WF (1996) A non-canonical genetic code in the early diverging eukaryotic lineage. EMBO (Eur Mol Biol Organ) J 15:2285-2290

Keeling PJ, Doolittle WF (1997) Widespread and ancient distribution of a noncanonical genetic code in diplomonads. Mol Biol Evol 14:895-901

Kent ML, Ellis J, Fournie JW, Dawe SC, Bagshaw JW, Whitaker DJ (1992) Systemic hexamitid (Protozoa: Diplomonadida) infection in seawater pen-reared Chinook salmon Oncorhynchus tshawytsha. Dis Aquat Org 14:81-89

Kulda J, Lom J (1964) Remarks on the diplomastigine flagellates from the intestine of fishes. Parasitology 54:753-762

Lavier G (1936) Sur la structure des Flagellés du genre Hexamita Dujardin. C R Séances Soc Biol 121:1177-1180

Lester RJG (1974) Parasites of Gasterosteus aculeatus near Vancouver, British Columbia. Syesis 7:195-200

Moore E (1922a) Description of Octomitus salmonis. In: Annu Rep NY State Conservation Committee No 12, New York State Conservation Department, Albany, NY, p 69-76

Moore E (1922b) Octomitus salmonis, a new species of intestinal parasite in trout. Trans Am Fish Soc 52:74-97

Moroff T (1903) Beitrag zur Kenntnis einiger Flagellaten. Arch Protistenkd 3:92-94

Poppe TT, Mo TA, Iversen L (1992) Disseminated hexamitosis in sea-caged Atlantic salmon Salmo salar. Dis Aquat Org 14:91-97

Poynton SL, Morrison CM (1990) Morphology of diplomonad flagellates: Spironucleus torosa n. sp. from Atlantic cod Gadus morhua L., and haddock Melanogrammus aeglefinus (L.) and Hexamita salmonis Moore from brook trout Salvelinus fontinalis (Mitchill). J Protozool 37:369-383

Poynton SL, Sterud E (2002) Guidelines for species descriptions of diplomonad flagellates from fish. J Fish Dis 25:15-31

Poynton SL, Fraser W, Francis-Floyd R, Rutledge P, Reed P, Nerad TA (1995) Spironucleus vortens n. sp. from freshwater angel fish Pterophyllum scalare: morphology and culture. J Eukaryot Microbiol 42:731-742

Sandborn EB (1970) Cells and tissues by light and electron microscopy, Vol II. Academic Press, New York
Schmidt W (1919/1920) Untersuchung über Octomitus intestinalis truttae. Arch Protistenkd 40:253-289

Siddall ME, Hong H, Desser SS (1992) Phylogenetic analysis of the Diplomonadida (Wenyon, 1926) Brugerolle, 1975: evidence for heterochrony in protozoa and against Giardia lamblia as a 'missing link'. J Protozool 39:361-367

Stehr C, Whitaker DJ (1986) Host-parasite interaction of the myxosporeans Kudoa paniformis Kabata \& Whitaker, 1981 and Kudoa thyrsites (Gilchrist, 1924) in the muscle of Pacific whiting, Merluccius productus (Ayres): an ultrastructural study. J Fish Dis 9:505-517

Sterud E (1998a) Electron microscopical identification of the flagellate Spironucleus torosa (Hexamitidae) from burbot Lota lota (Gadidae) with comments upon its probable introduction to this freshwater host. J Parasitol 84:947-953

Sterud E (1998b) In vitro cultivation and temperature-dependant growth of two strains of Spironucleus barkhanus (Diplomonadida: Hexamitidae) from Atlantic salmon Salmo salar and grayling Thymallus thymallus. Dis Aquat Org 33:57-61

Sterud E (1998c) Ultrastructure of Spironucleus torosa Poynton \& Morrison, 1990 (Diplomonadida: Hexamitidae), in cod Gadus morhua (L.) and saithe Pollachius virens (L.) from south-eastern Norway. Eur J Protistol 34:69-77

Sterud E, Poynton SL (2002) Spironucleus vortens (Diplomonadida) in the ide, Leuciscus leuciscus (L.): a warm water hexamitid flagellate found in Northern Europe. J Eukaryot Microbiol 49:137-145

Sterud E, Mo TA, Poppe TT (1997) Ultrastructure of Spironucleus barkhanus $\mathrm{n}$. sp. (Diplomonadida: Hexamitidae) from grayling Thymallus thymallus (L.) (Salmonidae) and Atlantic salmon Salmo salar L. (Salmonidae). J Eukaryot Microbiol 44:399-407

Sterud E, Mo TA, Poppe TT (1998) Systemic spironucleosis in sea-farmed Atlantic salmon Salmo salar, caused by Spironucleus barkhanus transmitted from feral Arctic char Salvelinus alpinus? Dis Aquat Org 33:63-66

Uldal A, Buchmann K (1996) Parasite host relations: Hexamita salmonis in rainbow trout Oncorhynchus mykiss. Dis Aquat Org 25:229-231

Uzmann JR, Paulik GJ, Hayduk SH (1965) Experimental hexamitiasis in juvenile coho salmon (Oncorhynchus kisutch) and steelhead trout (Salmo gairdneri). Trans Am Fish Soc 94:53-61

Wenyon CM (1926) Protozoology. A manual for medical men, veterinarians and zoologists, Vol I. Bailliere, Tindall \& Cox, London

Woo PTK, Poynton SL (1995) Diplomonadida, Kinetoplastida and Amoebida (phylum Sarcomastigophora). In: Woo PTK (ed) Fish diseases and disorders, Vol 1. Protozoan and metazoan disorders. CAB International, Wallingford, p 27-96

Submitted: September 29, 2003; Accepted: February 6, 2004 Proofs received from author(s): June 14, 2004
Editorial responsibility: Wolfgang Körting,

Hannover, Germany 